\title{
Lack of Efficacy of SGLT2-i in Severe Pneumonia Related to Novel Coronavirus (nCoV) Infection: No Little Help from Our Friends
}

\author{
Antonio Carlo Bossi (D) · Franco Forloni · Paolo Luigi Colombelli
}

Received: May 9, 2020 / Published online: May 23, 2020

(C) The Author(s) 2020

Keywords: COVID-19 related pneumonia; SGLT2-inhibitors; Non-diabetic patients

Italy is facing a dramatic health emergency related to COVID-19 initially spreading from Wuhan, China, and subsequently worldwide. Lombardy is the Italian region with the highest prevalence of positive cases, hospitalized patients, and percentage of deaths, and this is of great concern. Thinking about a possible way to help our patients, we hypothesized that sodium-glucose cotransporter 2 inhibitors (SGLT2-i), used in subjects with type 2 diabetes, could be of a certain efficacy in non-diabetic patients with hypoxemia and interstitial lung edema due to SARS-CoV-2 infection. The main physiopathological reasons supporting the use of SGLT2-i are their ability to shift energy metabolism [1], to increase hematocrit [2], to determine glucose excretion with associated $\mathrm{Na}^{+}$loss, and increase in osmotic diuresis [3]. Moreover, SGLT2-i may block the $\mathrm{Na}^{+} / \mathrm{H}^{+}$antiporter, consequently reducing cytoplasmic $\mathrm{Na}^{+}$and $\mathrm{Ca}^{2+}$, thus offering cellular

\footnotetext{
A. C. Bossi $(\bowtie) \cdot$ F. Forloni

Endocrine Unit-Diabetes Regional Center, ASST

Bergamo Ovest, Treviglio, BG, Italy

e-mail: antonio_bossi@asst-bgovest.it;

acbossi@gmail.com

P. L. Colombelli

Internal Medicine Division, ASST Bergamo Ovest, Treviglio, BG, Italy
}

protection. SGLT2-i may selectively reduce interstitial volume with minimal change in blood volume, thus limiting the aberrant reflex neurohumoral stimulation that occurs in the setting of intravascular depletion [4]. Furthermore, SGLT2-i may exert anti-inflammatory properties in animal models [5]. Finally, non-diabetic subjects are also prescribed SGLT2-i to reduce the incidence of worsening heart failure or cardiovascular-related death.

On the basis of the aforementioned hypothetical activities, three non-diabetic hospitalized patients with severe bilateral interstitial COVID-19-related pneumonia were treated "offlabel" with SGLT2-i immediately after hospital admission. Patient 1 suffered also from allergic asthmatic bronchitis; patient 2 underwent coronary angioplasty in 2016; patient 3 , female did not previously take any medication. Patients were $50-60$ years of age and a mix of both men and women. They presented with fever, a respiratory rate greater than 30 breaths/min, and severe respiratory distress with $\mathrm{SpO} 2$ of $93 \%$ or less on room air at a resting state. At admission, lung CT scan showed multifocal patchy shadows or ground glass opacities located in the periphery, subpleural area, and bilateral lower lobes. Nasopharyngeal and oropharyngeal specimens tested positive for SARS-CoV-2; tests for other respiratory viruses and for bacterial pathogens tested negative. Patients were treated in accordance with international guidelines; moreover, 
after a complete explanation about possible risks and benefits, they signed an informed consent form for "off-label" adjunctive oral therapy with empagliflozin $10 \mathrm{mg}$ for 5-7 days.

Hematology and biochemistry laboratory testing revealed a variable evolution in inflammatory markers. Control chest imaging did not show complete reduction in interstitial lung involvement during the patients' hospital length of stay (LOS). The patients described here were selected and are younger than the patients we typically take care of in our ward. Nevertheless, they required attention because of their symptoms and hypoxia caused by the COVID-19-related pneumonia. Usually, between 12 and 16 days are required for symptoms to lessen and to see signs improvement (unless complications occur). Unfortunately, we did not observe any reduction in the LOS or any favorable action related to the SGLT2-i dose received by the patients. Expected potential benefits might have led to a reduction of interstitial lung imbibition, to a possible metabolic energy shift, and potentially to an inflammatory response improvement. Not knowing whether there could be an effect and a need to systematically study the clinical application of SGLT2-i treatment in nondiabetic patients suffering from COVID-19 severe pneumonia hospitalized in an internal medicine ward, our anecdotal experience did not show any of the pathophysiologic changes we postulated.

\section{ACKNOWLEDGEMENTS}

Funding. No funding or sponsorship was received for this study or publication of this article.

Authorship. All named authors meet the International Committee of Medical Journal Editors (ICMJE) criteria for authorship for this article, take responsibility for the integrity of the work as a whole, and have given their approval for this version to be published.

Disclosures. Antonio C. Bossi, Franco Forloni and Paolo L. Colombelli have nothing to disclose.
Compliance with Ethics Guidelines. Ethical approval was waived by the ethics committee (Comitato Etico di Bergamo - ASST Papa Giovanni 23). Informed consent to take part in the study was obtained from the patients.

Open Access. This article is licensed under a Creative Commons Attribution-NonCommercial 4.0 International License, which permits any non-commercial use, sharing, adaptation, distribution and reproduction in any medium or format, as long as you give appropriate credit to the original author(s) and the source, provide a link to the Creative Commons licence, and indicate if changes were made. The images or other third party material in this article are included in the article's Creative Commons licence, unless indicated otherwise in a credit line to the material. If material is not included in the article's Creative Commons licence and your intended use is not permitted by statutory regulation or exceeds the permitted use, you will need to obtain permission directly from the copyright holder. To view a copy of this licence, visit http:// creativecommons.org/licenses/by-nc/4.0/.

\section{REFERENCES}

1. Mudaliar S, Alloju S, Henry RR. Can a shift in fuel energetics explain the beneficial cardiorenal outcomes in the EMPA-REG OUTCOME study? A unifying hypothesis. Diabetes Care. 2016;39:1115-22.

2. Inzucchi SE, Zinman B, Fitchett D, et al. How does empagliflozin reduce cardiovascular mortality? Insights from a mediation analysis of the EMPA-REG OUTCOME trial. Diabetes Care. 2018;41:356-63.

3. Verma S, McMurray JJ. SGLT2 inhibitors and mechanisms of cardiovascular benefit: a state-of-the-art review. Diabetologia. 2018;61:2108-17. https://doi. org/10.1007/s00125-018-4670.

4. Baartscheer A, Schumacher CA, Wust RC, et al. Empagliflozin decreases myocardial cytoplasmic $\mathrm{Na}^{+}$ through inhibition of the cardiac $\mathrm{Na}^{+} / \mathrm{H}^{+}$exchanger in rats and rabbits. Diabetologia. 2017;60:568-73.

5. Bonnet F, Scheen AJ. Effects of SGLT2 inhibitors on systemic and tissue low-grade inflammation: the potential contribution to diabetes complications and cardiovascular disease. Diabetes Metab. 2018;44:457-64. 